\title{
ПАТОФИЗИОЛОГИЧЕСКИЕ АСПЕКТЫ И ГЕМОДИНАМИЧЕСКИЕ НАРУШЕНИЯ ПОЧЕК ПРИ НЕФРОПАТИИ, АССОЦИИРОВАННОЙ С АНТИФОСФОЛИПИДНЫМ СИНДРОМОМ
}

\section{PATHOPHYSIOLOGICAL ASPECTS AND HEMODYNAMIC RENAL DISORDERS IN NEPHROPATHY ASSOCIATED WITH ANTIPHOSPHOLIPID SYNDROME}

M. Albakova

H. Albakova

L. Bogatyreva

D. Gagieva

Summary. The article is devoted to the problem of kidney pathology in adults and children with nephropathy associated with antiphospholipid syndrome (APS). Nephropathy is part of the clinical picture of APS. Thrombotic microangiopathy (TMA), which is a special type of vascular lesion in the microvasculature of various organs, is the cornerstone of nephropathy in APS. APS-nephropathy (APSN) is a predictively unfavorable independent disease. The clinical picture of APS-associated nephropathy is characterized by a variety of severity of clinical symptoms. The main symptoms of APS-nephropathy, which form the clinical variants of APSN, are described. The differences in the course of APS-associated nephropathy among men, women and children are shown.

Keywords: antiphospholipid syndrome (APS), vascular disorders, kidneys.

\author{
Албакова Маддан Хасолтановна \\ К.м.н., дочент, Ингушский государственный \\ университет, г. Магас \\ albakova2017@mail.ru \\ Албакова Хадижет Асхабовна \\ Старший преподаватель, Ингушский \\ государственный университет, г. Магас \\ Богатырева Лидия Николаевна \\ К.м.н., доцент, Ингушский государственный \\ университет, г. Магас \\ Гагиева Долатхан Алиевна \\ К.м.н., дочент, Ингушский государственный \\ университет, г. Магас
}

Аннотация. Статья посвящена проблеме патологии почек у взрослых и детей при нефропатии, ассоциированной с антифосфолипидным синдромом (АФС). Нефропатия является частью клинической картины АФС. В основе нефропатии при АФС лежит тромботическая микроангиопатия (ТМА), представляющая собой особый тип поражения сосудов микроциркуляторного русла различных органов. Прогностически неблагоприятным самостоятельным заболеванием является АФС-нефропатия (АФСН). Клиническая картина АФС-ассоциированной нефропатии отличается многообразием тяжести клинических симптомов. Описаны основные симптомы АФС-нефропатии, формирующие клинические варианты АФСН. Показаны различия в течении АФС-ассоциированной нефропатии среди мужчин, женщин и детей.

Ключевые слова: антифосфолипидный синдром (АФС), сосудистые нарушения, почки.

ко-морфологические особенности, характер течения, факторы, влияющие на прогноз лечения, при нефропатии, ассоциированной с антифосфолипидным синдромом. Высокая частота сосудистого поражения почек при АФС, полиморфизм его клинических проявлений объясняется большой протяженностью сосудистого русла почек и возможностью локализации тромботического процесса на любом его уровне - от основного ствола почечной артерии и ее ветвей до внутрипочечных артериол, гломерулярных капилляров и почечных вен. Клиническая картина определяется не только локализацией, но и распространенностью тромбообразования, темпом развития и степенью тромботической окклюзии, одно- или двусторонним характером процесса [2].

Нефропатия, как правило, является частью клинической картины АФС, сочетаясь, как правило, с пораже- 
нием ЦНС, сердца, периферических артерий или с акушерской патологией, реже - с венозными тромбозами [4]. На основе новых клинико-диагностических критериев АФС возможно и изолированное тромбоокклюзивное поражение внутрипочечных сосудов в отсутствие тромбозов крупных артериальных или венозных стволов. В основе нефропатии при АФС лежит тромботическая микроангиопатия (ТМА), представляющая собой особый тип поражения сосудов микроциркуляторного русла различных органов - окклюзию тромбами, содержащими фибрин и агрегированные тромбоциты, артерий малого калибра, артериол и капилляров в отсутствие признаков воспаления сосудистой стенки. TMA сопровождается разнообразием заболеваний, однако признаки поражения почек морфологические при этой патологии неспецифичны и могут быть представлены как острыми, так и хроническими изменениями. Острые изменения включают в себя распространенный тромбоз капилляров клубочков и внегломерулярных сосудов при светооптической микроскопии с отеком эндотелиальных клеток, отслойкой их от базальной мембраны и расширением субэндотелиального пространства, в котором накапливается рыхлый мембраноподобный материал, выявляемый при электронно-микроскопическом исследовании. Хроническую ТМА трудно диагностировать даже морфологически, поскольку при длительном течении она представлена картиной диффузного нефросклероза, а при меньшей продолжительности болезни фиброзные изменения сосудов и интерстиция носят неспецифический очаговый характер и не всегда расцениваются как проявления сосудистой патологии [2].

Поражение почек при АФС, как отмечалось выше, происходит в результате реноваскулярных тромбозов с вовлечением почечных артерий, внутрипаренхиматозных артерий, клубочковых капилляров или почечных вен с развитием ТМА внутрипочечных сосудов. Диагностика АФС-нефропатии требует наличия одного или нескольких острых или хронических типичных внутрипочечных поражений по результатам гистологии после исключения других причин почечной микроангиопатии. Обострение нефропатии, связанной с системной красной волчанкой (СКВ), прогрессирующее хроническое заболевание почек и ранняя потеря функции почечного трансплантата также являются частью спектра клинических проявлений поражения почек при АФС [1].

Основной формой поражения почек при АФС является АФС-нефропатия, которая выявляется в 90-100\% случаев у больных с первичным АФС с признаками поражения почек [6]. Термин «АФС-ассоциированная нефропатия» был предложен D. Nochy и соавт., который означал тромбоокклюзивное поражение мелких вну- трипочечных сосудов при АФС [5]. АФС-нефропатия является самостоятельным заболеванием, прогностически неблагоприятным органным проявлением первичного антифосфолипидного синдрома. Прогноз нефропатии, ассоциированной с антифосфолипидным синдромом при естественном течении заболевания неблагоприятен, поскольку 10-летняя почечная выживаемость составляет 50\% пациентов [3]. В настоящее время появились новые клинические, лабораторные и экспериментальные данные, позволяющие расширить представления о характере патофизиологических и гемодинамических нарушениях почек при нефропатии, ассоциированной с антифосфолипидным синдромом.

Клиническая картина АФС-ассоциированной нефропатии в зависимости от локализации тромбозов в сосудистом русле почек, протяженности и темпа развития процесса тромботической окклюзии, варьирует от острого повреждения почек и тяжелой артериальной гипертензии (АГ) до минимального мочевого синдрома, мягкой или умеренной артериальной гипертензии и медленно прогрессирующего нарушения функции почек. К основным и синдромам АФС-нефропатии относятся:

- артериальная гипертензия, которая обусловлена активацией ренин-ангиотензин-альдостероновой системы в ответ на ишемию почек;

- нарушение функции почек, которое проявляется в раннем изолированном снижение СКФ; в почечной недостаточности, как правило, имеющей медленно прогрессирующий характер; в распространенности острого повреждения почек до $20 \%$ [6].

- мочевой синдром, который в большинстве случаев представлен умеренной изолированной протеинурией менее 1,5 г/сут [6]. Протеинурия нефротического диапазона наблюдается в редких случаях изолированной АФС-нефропатии. Менее чем у $50 \%$ пациентов отмечается микрогематурия [1].

АФС-нефропатия редко проявляется как острая почечная тромботическая микроангиопатия, представляющая собой наиболее тяжелую форму острой АФС-нефропатии [6]. Это клиническое проявление связано с быстрым снижением функции почек с различными степенями гематурии и протеинурии. Острое течение характеризуется развитием остронефритического синдрома с быстро нарастающей креатининемией. В наиболее тяжелых случаях возникает быстро прогрессирующая почечная недостаточность, как правило, в сочетании с тяжелой АГ [1].

Основные клинические симптомы АФС-ассоциированной нефропатии - АГ, нарушение функции почек 
и мочевой синдром, в различных сочетаниях формируют три основных клинических варианта АФСН: синдром сосудистой нефропатии, остронефритический и нефротический синдромы. Ранним признаком АФС-ассоциированной нефропатии является нарушение функции почек, которое проявляется изолированным снижением СКФ, на несколько лет опережающим нарушение азотовыделительной функции почек. Выявлены различия в течении АФС-ассоциированной нефропатии среди мужчин и женщин. У мужчин болезнь манифестирует в среднем на 9 лет позже, чем у женщин преимущественно внепо- чечными проявлениями, в то время как у женщин преобладает поражение почек [3].

В заключение отметим, что новые клинические и лабораторные исследования особенностей клинико-морфологической картины, как собственно поражения почек, так и гемодинамических нарушений позволяет развернуто охарактеризовать АФС-нефропатию как новую форму тромботической микроангиопатии, и разработать на их основе основные принципы и методы ее диагностики и лечения.

\section{ЛИТЕРАТУРА}

1. Головач И.Ю., Егудина Е. Д., Рекалов Д. Г. Поражение почек на фоне антифосфолипидного синдрома // Рос̌ki. — 2019. — 8 (3). — С. 161-173.

2. Козловская Н. Л. Сосудистое поражение почек при антифосфолипидном синдроме// Нефрология и диализ. - 2006. - № 3, Т. 8. - С. $206-216$.

3. Метелева Н. А. Поражение почек при первичном антифосфолипидном синдроме: автореферат дис. ... кандидата медицинских наук. — Москва, 2004.— $24 \mathrm{c}$.

4. Daugas E., Nochy D., Thi Huong D. L. et al. Antiphospholipid syndrome nephropathy in systemic lupus erythematosus // Am Soc Nephrol.— 2002.— № 13.— P. 42-52.

5. Nochy D., Daugas E., Droz D. et al. The intrarenal vascular lesions associated with primary antiphospholipid syndrome // Am. Soc. Nephrol.— 1999.— № 10.— P. 507-519.

6. Sinico RA, Cavazzana I, NuzzoM, et al. Renal involvement inprimary antiphospholipid syndrome: retrospective analysis of 160 patients // Clin J Am Soc Nephrol. 2010. — Jul, 5(7). - P. 1211-1217.

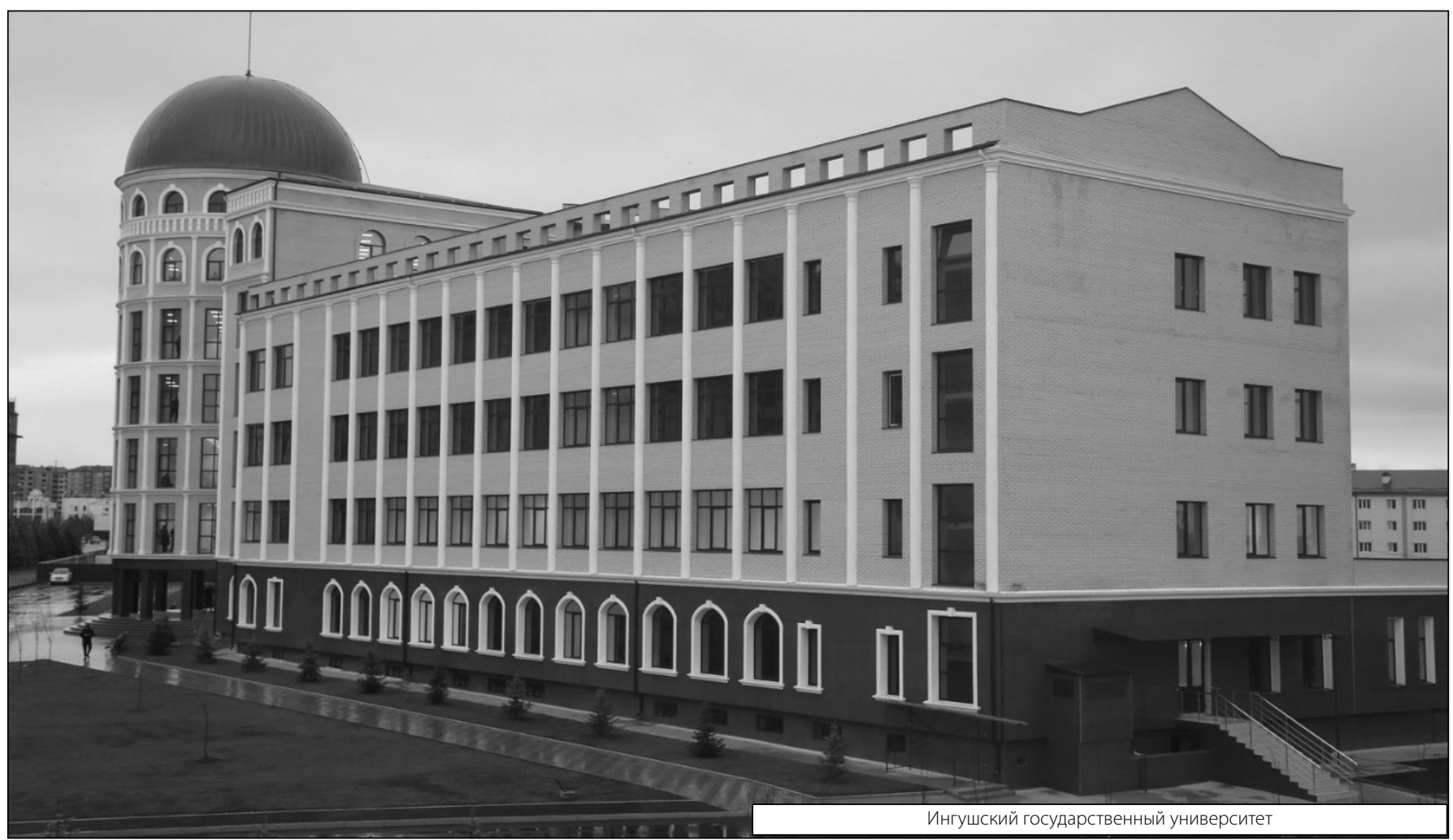

